\title{
The impact of sustained hyperglycemia, metabolic memory and hba1c variability in the development of chronic complications in patients with type 1 diabetes
}

\author{
Larissa Carolina Garcia Franco da Rosa*, Marcus Miranda, Joana Dantas, Debora Baptista Araújo, \\ Marcus Vinicius Pinto, Leticia Maria Alcantara Margallo, João Batista Jornada Ben, Melanie Rodacki, \\ Lenita Zajdenverg
}

From 20th Brazilian Diabetes Society Congress

Porto Alegre, Brazil. 11-18 November 2015

\section{Background}

Sustained hyperglycaemia has been linked to the development of chronic complications of type 1 diabetes (T1D) in most populations, especially if it occurs in the first few yrs. of the disease. However, this has been poorly studied in the Brazilian multi-ethnic population.

\section{Objectives}

To assess if there is an association between the development of chronic complications (retinopathy-DR, nephropathy-DN, peripheral neuropathy- PN and cardiac autonomic neuropathy-CAN) in patients with T1D and 1) the mean glycated Haemoglobin during their followup since diabetes onset (mHbA1c); 2) the standard deviation (SD) of HbA1c over this period, 3) the HbA1c in the first 3 yrs. of disease (1st 3 yr.) and 4) the current HbA1c.

\section{Materials and methods}

This retrospective study included patients with T1D $\geq 5$ yrs. that were followed in a specialized center. Epidemiological, clinical and laboratory data were obtained by reviewing the medical charts. mHbA1c, HbA1c in the 1st $3 \mathrm{yr}$ of T1D and SD of HbA1c were calculated. DR was evaluated by ophthalmoscopy. Increased urinary albumin excretion (IUAE) was defined according to the ADA criteria. CAN was diagnosed through a Questionnaire and Variability of

* Correspondence: larissa.gfr@gmail.com

Universidade Federal do Rio de Janeiro, Rio de Janeiro, Brazil heart rate tests. PN was defined by Neuropathy Symptoms Score and Neuropathy Disability Scores.

\section{Results}

199 patients were assessed (54.7\% women) with mean age and T1D duration of $27.9 \pm 9.7,17.1 \pm 7.3$ yrs., respectively. Their mean mHbA1c was $8.38 \pm 1.58 \%$. DR, IUAE, PN and CAN were seen in 10.8\% (12/111), 17.7\% (33/ $188), \mathrm{PN}$ in $35 \%(23 / 64)$ and $\mathrm{CAN}$ in $31.3 \%(33 / 107)$. Patients with IUAE had higher mHbA1c levels than others $(8.95 \pm 1.53$ vs. $7.99 \pm 1.18 ; \mathrm{p}=0.010)$. MhbA1c also differed between those with $\mathrm{PN}$ and others $(9.12 \pm 1.82$ vs. $7.65 \pm 0.93 ; p=0.001)$. Although there was no association between mHbA1c and DR, the mean HbAlc in the last 10 yrs. was higher in those with DR than others $(7.98 \pm 1.25$ vs. $9.68 \pm 1.85 ; \mathrm{p}=0.001)$. The SD of HbA1c was also higher in those with DR and CAN than those without these complications $(p=0.004$ and $p=0.003$, respectively). The HbA1c 1st 3yr. was higher in patients with DR $(12.41 \pm 5.06$ vs. $7.33 \pm 0.86 ; \mathrm{p}=0.001)$ and in those with $\mathrm{DN}(9.35 \pm 0.45$ vs. $7.71 \pm 0.81 ; \mathrm{p}=0.036)$ than others. Current HbA1c $(8.35 \pm 1.56)$ was not associated with either of these complications.

\section{Conclusions}

Sustained hyperglycemia, especially in the first years of the disease, and $\mathrm{HbClc}$ variability over time have been linked to the development of chronic complications in our population. 
- Convenient online submission

- Thorough peer review

- No space constraints or color figure charges

- Immediate publication on acceptance

- Inclusion in PubMed, CAS, Scopus and Google Scholar

- Research which is freely available for redistribution 